\title{
O PROGRAMA SEGUNDO TEMPO E SEU PROCESSO DE CAPACITAÇÃO: análise e proposições
}

\author{
Heitor de Andrade Rodrigues \\ Luiz Gustavo Bonatto Rufino² \\ Osmar Moreira de Souza Júnior ${ }^{3}$ \\ Silvano da Silva Coutinho
}

\section{RESUMO}

O presente estudo objetivou refletir sobre o modelo de capacitação do "Programa Segundo Tempo", buscando-se realizar proposições visando o aprofundamento da compreensão sobre a capacitação regional, incluindo novos olhares para esse processo. Para isso, realizou-se uma discussão sobre os temas: o processo de capacitação; os limites impostos ao atual modelo de capacitação; possíveis caminhos para qualificação do trabalho. Por fim, apresentou-se uma proposta complementar ao atual modelo de capacitação, a partir dos pressupostos da racionalidade prática, visando o aprimoramento dos processos de capacitação, valorizando ações reflexivas oriundas da prática, para que sejam viabilizadas melhorias efetivas nas ações do programa.

Palavras-chave: Projeto social; Pedagogia do esporte; Formação profissional.

1 Mestre em Ciências da Motricidade (UNESP/ Rio Claro) e doutorando em Educação Física (UNICAMP/ Campinas). Contato: triheitor@yahoo.com.br.

2 Mestrando do Programa Interdisciplinar de Desenvolvimento Humano e Tecnologias da Unesp Rio Claro. Graduado em Educação Física (bacharel) por esta mesma instituição. Contato: gustavo_rufino_6@hotmail.com.

3 Professor assistente do Departamento de Educação Física e Motricidade Humana (DEFMH) da UFSCar, mestre em Ciências da Motricidade pela Unesp - Rio Claro e doutorando em Educação Física pela Unicamp. Contato: osmar@ufscar.br.

4 Professor Assistente do Curso de Educação Física da Universidade Estadual do Centro-Oeste - UNICENTRO, pós doutorando no Programa de Enfermagem em Saúde Publica - Universidade de São Paulo - EERP/USP e bolsista de pós doutorado Júnior - CNPq. Contato: silvano.unicentro@gmail.com. 


\section{INTRODUÇÃO}

O Ministério do Esporte assume como sua missão a responsabilidade de construir uma Política Nacional de Esporte, que além de desenvolver o esporte de alto rendimento, atenda às demandas da inclusão social por meio do esporte, garantindo o acesso gratuito à prática esportiva, a qualidade de vida e o desenvolvimento humano à população brasileira (MINISTÉRIO DO ESPORTE, 2012).

Sob a égide desta Política Nacional de Esporte, do ponto de vista estratégico, o Ministério do Esporte possui três diferentes frentes de atuação que compreendem a Secretaria Nacional de Esporte, Educação, Lazer e Inclusão Social; a Secretaria Nacional de Futebol e Defesa dos Direitos do Torcedor e a Secretaria Nacional de Esporte de Alto Rendimento.

O interesse do presente estudo está voltado para a Secretaria Nacional de Esporte, Educação, Lazer e Inclusão Social (SNELIS), que surge no ano de 2011, por meio da fusão das antigas Secretarias Nacionais de Esporte Educacional (SNEED) e de Esporte de Lazer (SNEL) e, mais especificamente, circunscreve-se à análise do projeto com maior representatividade desta pasta, do ponto de vista do número de beneficiados atendidos, que é o Programa Segundo Tempo (PST).

O Programa Segundo Tempo (PST), é uma política pública de promoção de vivências de esporte numa perspectiva pedagógica em âmbito nacional. De acordo com Hansen, Perim e Oliveira (2009), este programa apresenta como principal objetivo:

(...) democratizar o acesso à prática e à cultura do esporte de forma a promover o desenvolvimento integral de crianças, adolescentes e jovens, como fator de formação da cidadania e melhoria da qualidade de vida, prioritariamente daqueles que se encontram em áreas de vulnerabilidade social (HANSEN; PERIM; OLIVEIRA, 2009, p. 8).

Para isso, a principal estratégia utilizada refere-se ao estabelecimento de alianças e parcerias institucionais, por meio de convênios formalizados com governos estaduais e municipais ou organizações não governamentais, bem como entidades nacionais e internacionais, sejam elas públicas ou privadas, sem fins lucrativos (HANSEN; PERIM; OLIVEIRA, 2009).

Em uma visão histórica, podemos elencar que as políticas de esporte no Brasil, de maneira geral, não privilegiaram o esporte em uma perspectiva educacional, estando mais vinculados à questão do rendimento, sempre atrelada à imagem social do país. De acordo com Bracht (2011), o fenômeno esportivo, no Brasil, situa-se numa posição marginal frente a setores como a economia, a saúde, a educação e a habitação.

Contudo, o autor reconhece que, embora não seja compreendido como uma prioridade fundamental das políticas públicas governamentais, o esporte sempre foi alvo de especulação política, dada a sua significação sociopolítica, ou seja, "não elegê-lo como prioridade, entretanto, não significa ignorá-lo" (BRACHT, 2011, p. 90).

Esse lastro histórico de negligência do esporte em uma perspectiva pedagógica e ligada ao lazer impediu que a perspectiva em torno dessa manifestação corporal pudesse se tornar majoritária em termos de políticas públicas no Brasil. No entanto, projetos como o Programa Segundo Tempo, apresentam a importância de reaver essa 
defasagem histórica, dada a importância de se compreender o fenômeno esportivo educacional e de lazer na atualidade. Para Bracht (2011):

Com isso, queremos manifestar que o esporte, enquanto atividade de lazer deve, em nosso entendimento, ser a prioridade nas intervenções do poder público no setor. Nesse sentido, ele precisa ser entendido como um elemento de cultura/lazer e ser inserido no plano das políticas culturais de lazer e como tal estar integrado às outras políticas sociais. Também porque, assim, outras manifestações da nossa cultura corporal de movimento, ainda não esportivizadas, não precisam ficar subordinadas ao conceito de esporte e moldarem-se nele para receber atenção do poder público (BRACHT, 2011, p. 96).

Tubino (2010) aponta que, finalmente, foi apenas em 2004 que o movimento esportivo educacional ganhou um grande impulso com a criação do "Projeto Segundo Tempo", do Ministério do Esporte, em parceria com o Ministério da Educação, operacionalizado pela Secretaria de Esporte Educacional, destinado aos alunos da rede pública do ensino fundamental e médio, principalmente em áreas de carência e vulnerabilidade social. $\mathrm{O}$ autor afirma ainda que "esse projeto, além das práticas esportivas, também compreendeu desde seu início a implementação de material esportivo e de reforço alimentar" (TUBINO, 2010, p. 131).

Para que os objetivos do programa possam ser atendidos de maneira clara e efetiva há uma série de diretrizes a serem cumpridas, desde os processos de abertura de convênios, passando pela etapa de prestação de contas e, ainda, por todo o acompanhamento pedagógico necessário ao bom andamento do programa.
Neste sentido, tomaremos por base a análise do Projeto Padrão do programa, que adota como estratégia a implantação de núcleos, a partir da formalização de um convênio entre o Ministério do Esporte e uma instituição pública ou privada sem fins lucrativos.

Este convênio firmado pode abrigar um ou mais núcleos, de acordo com o potencial de atendimento da(s) localidade(s) atendida(s), sendo a configuração de um núcleo caracterizada pela composição de um grupo de 100 beneficiados que atendam ao perfil do público alvo do programa, ou seja, crianças adolescentes e jovens, entre 6 e 17 anos, prioritariamente matriculados em escolas públicas e/ou oriundos de áreas de vulnerabilidade social.

A estes beneficiados o núcleo deve garantir o mínimo de duas modalidades esportivas coletivas e uma individual, além de atividades complementares, sob a orientação de um profissional de Educação Física no papel de coordenador de núcleo e no mínimo um monitor de atividade esportiva, em geral, estudante de Educação Física. Além disso, é necessário que as atividades do núcleo atendam aos beneficiados no contraturno escolar, com a frequência mínima de três vezes por semana e duas horas diárias.

Com relação aos recursos humanos, o mínimo necessário para o funcionamento de um convênio consiste em um coordenador geral, um coordenador pedagógico, um coordenador de núcleo para cada núcleo em funcionamento no convênio e um monitor de atividade esportiva para cada um destes núcleos.

Para oferecer um suporte pedagógico e administrativo aos convênios, o Ministério do Esporte implantou desde 
2008 as Equipes Colaboradoras. As Equipes Colaboradoras estão inseridas em uma rede de acadêmicos ligados às Instituições de Ensino Superior, espalhadas por todo o país, que formam grupos com a finalidade de realizar o acompanhamento administrativo e principalmente, pedagógico dos convênios, de forma relativamente regionalizada. As ações destas equipes envolvem a avaliação dos Projetos Pedagógicos de Núcleo (PPN), o desenvolvimento de capacitação de coordenadores e a avaliação das ações no cotidiano do núcleo.

Atualmente o Programa Segundo Tempo dispõe de um modelo de capacitação presencial e integrada com vídeo aulas sobre os diversos assuntos contidos nas diretrizes básicas do programa. A capacitação pedagógica direciona-se aos coordenadores pedagógicos, setoriais, de núcleo e monitores do programa. Há a obrigatoriedade de que todo convênio seja capacitado para desenvolver suas atividades. Essa capacitação tem como finalidade discutir junto aos profissionais dos convênios, os fundamentos e diretrizes do programa.

De acordo com Sousa et al. (2010), o objetivo da capacitação de recursos humanos do Programa Segundo Tempo é constituir padrões conceituais, operacionais e metodológicos minimamente homogêneos, abordando aspectos gerenciais e pedagógicos por meio da formação de multiplicadores, devendo ocorrer de forma regional e descentralizada.

Os autores apontam ainda que o processo de capacitação é composto por duas fases: uma nacional e outra regional. A fase nacional envolve os coordenadores gerais, pedagógicos e setoriais e conta com a atuação de instituições parceiras do Programa Segundo Tempo, objetivando aprofun- dar os debates sobre o esporte como fator de inclusão social, discutir procedimentos de implantação, desenvolvimento e gestão do programa (SOUSA et al., 2010).

Já a fase regional é presencial e qualifica os coordenadores de núcleos em relação às questões pedagógicas, técnicas e de gestão necessárias ao desenvolvimento das parcerias e com foco nas atividades dos núcleos. Há ainda nessa fase a orientação sobre a capacitação dos monitores de responsabilidade dos coordenadores de cada núcleo (SOUSA et al., 2010).

No entanto, como toda política pública que deve abranger uma perspectiva política ampliada em um país com as dimensões do Brasil, como é o caso do Programa Segundo Tempo, há algumas limitações no desenvolvimento das capacitações, e para isso, é importante, em um primeiro momento, compreendermos como estas capacitações se desenvolvem para, posteriormente, propormos formas de complementação das mesmas, visando a melhoria efetiva das ações pedagógicas relacionadas a este programa.

Assim, o objetivo do presente trabalho foi refletir sobre o atual modelo de capacitação do Programa Segundo Tempo, especificamente o processo de capacitação regional de coordenadores de núcleo e a partir das discussões apresentadas, buscou-se realizar proposições visando o aprofundamento do processo de capacitação, incluindo novos olhares para esse processo.

\section{O PROCESSO DE CAPACITAÇÃO}

O processo de capacitação regional relacionado ao Programa Segundo Tempo (PST) tem sido realizado, preferencialmente, nos próprios municípios sedes dos convênios. 
A partir do aviso de ordem de início, a Equipe Colaboradora realiza o contato com o convênio, de modo a agendar a realização da capacitação entre os dias 30 e 60 contados a partir da data de funcionamento efetivo das atividades do convênio.

Toda a estrutura física para realização do evento fica a cargo do convênio. Toda estrutura logística (refeições, coffee break, cronograma, entre outros aspectos organizacionais) são de responsabilidade conjunta do Ministério do Esporte e do convênio e, nesse sentido, tem o acompanhamento direto das equipes colaboradoras. Por fim, toda a parte pedagógica com relação as palestras, dinâmicas, vivências práticas e apresentação e discussão das vídeo aulas, são de responsabilidade da Equipe Colaboradora.

A capacitação é realizada em 2 dias. São apresentados 8 temas: 1) Fundamentos do PST; 2) Fundamentos do lazer e da animação cultural; 3) Corpo, gênero e sexualidade; 4) Desenvolvimento e aprendizagem motora; 5) Questões da deficiência e as ações no PST; 6) Organização e desenvolvimento pedagógico do esporte no PST; 7) Procedimentos metodológicos para o PST e, 8) Planejamento do PST.

Os temas são apresentados em forma de palestra presencial ou por vídeo-aulas. Após a apresentação do tema, os participantes são motivados a discutir o tema com os autores ou com algum membro da Equipe Colaboradora responsável pelo tema.

No presente estudo incluímos inquietações oriundas dos resultados da capacitação de 10 convênios de municípios do interior do estado de São Paulo que foram organizadas ou acompanhadas pela Equipe Colaboradora 21 (EC 21).
No período de 30 de março a 28 de outubro de 2011 foram capacitados 135 coordenadores, sendo 9 coordenadores gerais, 10 coordenadores pedagógicos, 3 coordenadores setoriais, 105 coordenadores de núcleos e 8 monitores de atividades esportivas.

Ao final da capacitação, é realizada uma avaliação pedagógica, para verificar o nível de assimilação dos conteúdos, pelos participantes da capacitação. Essa avaliação é composta por 80 questões nas quais os participantes devem assinalar verdadeiro (V) ou falso (F).

Ao considerarmos o desempenho dos participantes nestas capacitações, temos uma média geral de acertos de $84,65 \%$. No entanto, quando são realizadas as avaliações nas visitas in loco, os avaliadores da EC21 têm verificado que os professores e monitores ainda possuem dificuldades ao transferirem o que aprenderam nas capacitações para o cotidiano do desenvolvimento de suas aulas.

Nos relatórios consolidados, que são construídos com base nas informações coletadas nas visitas, algumas características ficam mais evidentes em relação às dificuldades encontradas pelos professores e monitores no cotidiano dos núcleos: uso demasiado de filas muito longas; ausência de processos de avaliação efetivamente implantados; falta de elaboração do planejamento dentro de uma visão orgânica, em que este deva ser utilizado efetivamente para programar as atividades dos núcleos e, desta forma, por muitas vezes, o planejamento acaba se tornando apenas uma tarefa burocrática; falta de preocupação em realizar atividades com o objetivo de explorar as três dimensões dos conteúdos (procedimental, conceitual e atitudinal), entre outras. 
No atual modelo de capacitação, já colhemos bons frutos que possibilitaram ampliar o olhar dos professores e monitores envolvidos em relação às diretrizes e metas de um projeto de esporte educacional, no entanto, os resultados dos relatórios consolidados citados nos remetem a pensar em outras possibilidades de capacitação, de modo a continuar avançando com a intenção de suprir ainda mais as dificuldades, especialmente pedagógicas, dos professores e monitores para o desenvolvimento das ações no PST.

\section{RACIONALIDADE TÉCNICA: LIMITES IMPOSTOS AO ATUAL MODELO DE CAPACITAÇÃO}

Como é possível vislumbrar a partir dos dados apresentados, a capacitação de coordenadores de núcleo do Programa Segundo Tempo demonstra resultados satisfatórios quando avaliamos a apropriação dos conhecimentos teóricos veiculados nas diversas palestras do curso. Por outro lado, nas diversas oportunidades de visita in loco e observação da prática pedagógica dos coordenadores é possível afirmar que, na maioria dos casos, parece não haver uma transposição desses conhecimentos para o cotidiano de trabalho, na verdade esses conhecimentos parecem submergir frente à complexidade dos problemas enfrentados na prática.

Esse descompasso entre teoria e prática, ou dito de outro modo, essa incoerência entre o que as reflexões teóricas sugerem e o que de fato os professores fazem não é um problema novo, tendo sido amplamente explorado no campo da Educação e da Educação Física escolar.

É preciso reconhecer que diversos fatores convergem para configuração dessa realidade, dentre eles, destaca-se para os propósitos de nossa reflexão as características do modelo de formação/ capacitação adotado pelo Programa Segundo Tempo. Um curso de curta duração pautado em um currículo de base científica que privilegia as subdisciplinas da Educação Física, tais como a Aprendizagem Motora, a Pedagogia do Esporte, a Educação Física Adaptada, o Lazer, entre outras, e que é desenvolvido por professores especialistas em cada uma dessas áreas.

Nesse sentido, o curso de capacitação do Programa Segundo Tempo reproduz o modelo de formação da maioria dos cursos de graduação em Educação Física, o que Rangel e Betti (1996) definem como o currículo de orientação técnico-científica, o qual valoriza as disciplinas teóricas gerais e aplicadas e abre espaço ao envolvimento com as Ciências Humanas e a Filosofia. Ainda de acordo com Rangel e Betti (1996) nesse currículo o conhecimento flui da teoria para a prática, e a prática é entendida como a aplicação dos conhecimentos teóricos.

O currículo técnico-científico representa um avanço em relação ao currículo tradicional pautado nas disciplinas práticas, hegemônico nos cursos superiores de Educação Física no Brasil nas décadas de 1960 e 1970, no entanto, sofre inúmeras críticas por representar uma perspectiva de formação afinada a um modelo de racionalidade técnica.

No entendimento de Perez Gomez (1995) no modelo de formação de professores sustentado pela racionalidade técnica a atividade profissional é nomeadamente instrumental, dirigida para solução de problemas por meio da aplicação de teorias e técnicas científicas. 
Nessa forma peculiar de conceber a formação de professores, os cursos de formação incorporam a ideia de que a competência prática torna-se profissional quando sua fonte de resolução de problemas é o conhecimento científico sistematizado. Além disso, o modelo de racionalidade técnica justifica seus pressupostos no entendimento de que a pesquisa acadêmica rende conhecimento profissional útil, o qual deve ser ensinado aos estudantes, com vistas à solução dos problemas da prática (SCHON, 2000).

As consequências desse tipo de formação são apontadas por críticos de diversas áreas, os quais alertam que os profissionais formados a partir desse modelo normativo de currículo são incompetentes na resolução de problemas complexos, instáveis, incertos e conflituosos da prática (SCHON, 2000).

Nesse mesmo sentido, Zabalza (2004) compreende que, pelo fato da atuação profissional do professor assentar-se na aula, que se traduz em uma dinâmica fluida e dependente do contexto, é habitual que os planos de trabalho estabelecidos por estes professores acabem desviando-se do caminho esperado em virtude das circunstâncias externas. Portanto, é preciso compreender as aulas - sejam elas nas escolas ou em projetos esportivos e/ou sociais - e o trabalho docente, a partir de sua condição de multidimensionalidade, simultaneidade e imprevisibilidade.

Em oposição ao modelo de racionalidade técnica, excessivamente centrado nas dimensões acadêmicas, a partir de 1990, a discussão sobre a formação de professores deslocou-se para o terreno profissional, valorizando os saberes experienciais e a prática dos professores, bem como seu desenvolvimento pessoal e profissional (NÓVOA, 1995).

Dentre os pressupostos fundamentais a orientar essa mudança de foco está o entendimento de que a formação de professores não se constrói apenas com o acúmulo de conhecimentos da formação inicial, mas que parte significativa da formação acontece no contexto da prática profissional (NÓVOA, 1995).

Ou seja, a prática profissional no contexto específico do trabalho pode ser compreendida como um espaço privilegiado de produção de saberes e não um espaço de aplicação de teorias e técnicas.

Portanto, a partir de nossas experiências no programa, seja como professores nas capacitações ou avaliadores dos núcleos in loco, é possível afirmar que o modelo de capacitação adotado pelo Programa Segundo Tempo enfrenta as mesmas limitações de qualquer curso sustentado pelos pressupostos da racionalidade técnica. De forma mais específica, o atual modelo de capacitação do Programa Segundo Tempo parece não estar sendo suficiente para preparar os professores para lidarem com os problemas complexos, instáveis, incertos e conflituosos da prática.

É importante reconhecer que o atual modelo de capacitação tem suas virtudes e, considerando as dimensões continentais do Brasil, esse foi o modelo encontrado para atingir todos os coordenadores de núcleo de uma forma mais homogênea, pois, cada um destes atores, participantes do Programa Segundo Tempo, tem a oportunidade de receberem os mesmos conteúdos, em qualquer parte do Brasil. Com Equipes Colaboradoras compostas por professores residentes no mesmo estado ou na mesma região do convênio, há também, uma maior 
possibilidade de respeito às características regionais do público participante das capacitações.

Apesar disso, durante as visitas in loco, os professores da Equipe Colaboradora 21 observaram que ainda são inúmeras as dificuldades enfrentadas pelos coordenadores de núcleo na efetivação da proposta. Portanto, considera-se oportuno refletir sobre um modelo de capacitação que possa complementar as lacunas do atual modelo. Um modelo sustentado pelos pressupostos da racionalidade prática, no qual a prática seja entendida como eixo central da formação e os professores sejam tomados como produtores de conhecimento. Um modelo em que a produção acadêmica nas diferentes áreas de conhecimentos que estabelecem relação com as diretrizes do Programa, dialoguem com os dilemas enfrentados pelos profissionais na sua prática pedagógica, servindo como mediadora no processo, mas em uma relação hierárquica linear e não mais na condição de verdades absolutas assentadas em um estatuto acadêmico hierarquicamente superior.

\section{RACIONALIDADE PRÁTICA: POSSÍVEIS CAMINHOS PARA QUALIFICAÇÃO DO TRABALHO}

Buscando alternativas às limitações do modelo de racionalidade técnica Schon (2000) afirma que a pergunta central não deve ser mais como utilizar os conhecimentos oriundos das pesquisas científicas, mas como incorporar ao currículo o conhecimento de professores competentes e talentosos, o que denomina de talento artístico capaz de mediar de forma eficiente e eficaz as indeterminações da prática.
Assim, as propostas de Schon (2000) encaminham no sentido de aprender com a prática, mais especificamente aprender fazendo mediado por um instrutor experiente. Para tanto, propõe os conceitos de conhecimento na ação e reflexão na ação. O conhecimento na ação é caracterizado pelo ato de conhecer na ação, revelado pela execução espontânea do desempenho prático, um processo tácito sem deliberação consciente, o qual se manifesta no saber fazer.

A reflexão na ação caracteriza-se por um pensamento retrospectivo sobre o que está sendo feito ou o que foi feito. Portanto, a reflexão na ação pode ser efetivada durante a ação e após a ação. No primeiro caso há possibilidade de interferência na situação em desenvolvimento, um tipo de conhecimento que se encontra constrangido pelas pressões de tempo e espaço, e por solicitações psicológicas e sociais do contexto de prática. Já a reflexão sobre a ação (realizada após a ação) é uma maneira de descrever, analisar e avaliar o processo e o produto da intervenção, identificando as teorias, estratégias e crenças que embasaram a intervenção, uma espécie de consciencialização dos mecanismos envolvidos na ação.

Pautados nos trabalhos de Schon (2000), sobre a prática reflexiva, alguns autores vêm se esforçando para demonstrar como os professores aprendem por meio das experiências de trabalho. Gilbert e Trudel (2001), por exemplo, buscaram examinar como os treinadores de jovens esportistas aprendem por meio da experiência, para tanto, seis treinadores foram entrevistados e observados por mais de uma temporada.

Os resultados da pesquisa de Gilbert e Trudel (2001) demonstraram que todos os treinadores investigados desenvolveram e refinaram suas estratégias de treinamento 
por meio da prática reflexiva, sendo que essa reflexão esteve balizada por seis componentes, quais sejam: os dilemas/ problemas do treinamento, papel profissional, definição do problema, geração de estratégias, experimentação e avaliação.

Assim, no cotidiano de trabalho os treinadores se deparam com alguns problemas (dilemas do treinamento), os quais não estão dados ou prontos e precisam ser gerados, definidos pelos treinadores. Esse processo de definição do problema está vinculado ao papel profissional concebido pelo treinador, o qual está intimamente relacionado à sua filosofia de trabalho, aspectos que influenciam o que realmente será definido como problema do treinamento. A partir da definição do problema o treinador busca elaborar as estratégias de solução (geração de estratégias), em seguida as coloca em prática (experimentação) e posteriormente avalia o resultado.

Transferindo esses componentes/ fases do processo reflexivo para o contexto de atuação do coordenador de núcleo do Programa Segundo Tempo é possível vislumbrar o seguinte exemplo ilustrativo.

Durante o desenvolvimento de uma aula no Programa Segundo Tempo, o coordenador de núcleo vai se deparar com uma serie de dilemas, os quais podem estar relacionados com os alunos (indisciplina, número reduzido, número elevado, poucos conhecimentos prévios sobre a modalidade, meninos e meninas na mesma turma, diferentes faixas etárias na mesma turma, entre outros), com o espaço físico (quadra poliesportiva precária, quadra descoberta, ausência dos equipamentos necessários ao esporte, etc.), com os materiais (materiais insuficientes, materiais inadequados para faixa etária, ausência de material específico para modalidade) com a sua própria formação (desconhecimento da modalidade, dificuldade no relacionamento com os alunos de determinada faixa etária, pouca experiências com o esporte educacional, etc.), entre outras categorias de dilemas.

Nesse contexto, o coordenador deverá ter claro o seu papel profissional no Programa Segundo Tempo, para tanto, deve conhecer as diretrizes do programa e os objetivos a serem perseguidos. Esse entendimento é fundamental, tendo em vista que o mesmo será um dos critérios para definição dos problemas de sua aula. Ou seja, ao se deparar com a realidade problemática de uma aula o coordenador deve ser capaz de definir quais são os problemas mais relevantes, passíveis de serem refletidos em busca de uma solução. Esse processo está na dependência da visão atribuída pelo coordenador de núcleo sobre o seu papel profissional no PST.

Após a definição de um problema passível de reflexão, o coordenador de núcleo passa a buscar estratégias para solucionar o problema, na sequência experimenta a efetividade das mesmas, ou seja, coloca a estratégia em prática e posteriormente avalia o resultado.

Ao longo desse processo de experimentação-reflexão-experimentação o professor produz conhecimentos sobre o seu trabalho, conhecimento útil que lhe permite resolver os problemas que vão emergindo no cotidiano das aulas.

A grande contribuição de Gilbert e Trudel (2001) para os propósitos de nosso estudo é identificar os componentes ou as fases do processo reflexivo dos treinadores (Figura 1). Evidentemente, o objetivo da intervenção pedagógica de um coordenador de núcleo do PST é diferente de um 
treinador de esporte, apesar disso, acreditamos que as fases do processo reflexivo sejam muito parecidas, com exceção dos conteúdos de cada fase, os quais inevitavelmente serão diferentes, tendo em vista que os objetivos perseguidos são diferentes e consequentemente o processo de definição do problema e as fases subsequentes serão muito particulares.

\begin{tabular}{|l|l|}
\hline $1^{\circ}$ componente & Dilemas do treino/ aula \\
\hline $2^{\circ}$ componente & Papel profissional \\
\hline $3^{\circ}$ componente & Definição do problema \\
\hline $4^{\circ}$ componente & Geração de estratégias \\
\hline $5^{\circ}$ componente & Experimentação \\
\hline $6^{\circ}$ componente & Avaliação \\
\hline
\end{tabular}

Fig. 1- Componentes do processo refletivo - Adaptado de Gilbert e Trudel (2001)

Ainda de acordo com Gilbert e Trudel (2001) a prática reflexiva dos treinadores e, mais especificamente, a capacidade dos treinadores selecionarem opções para solucionar os problemas está na dependência ou é influenciada por algumas características, tais como o acesso dos treinadores aos seus pares, o estágio de aprendizagem do treinador (iniciante, experiente etc.), as características dos problemas (níveis de desafio) e o contexto de treinamento (influência de familiares e dos gestores da equipe e do campeonato). Além disso, é preciso haver uma predisposição para refletir sobre a prática, ou seja, não são todos treinadores que conseguem ou estão implicados no processo reflexivo.

\section{UMA PROPOSTA DE INTERVENÇÃO}

Portanto, é a partir do reconhecimento de que os professores produzem saberes por meio das experiências de trabaIho e que esse processo pode ser sistematizado em algumas fases/ componentes, que identificamos uma possibilidade bastante fértil de capacitação dos coordenadores de núcleo afinada a um modelo de racionalidade prática.

Para tanto, consideramos oportuno criar ambientes facilitadores ao desenvolvimento da prática reflexiva, ou seja, espaços nos quais os professores tenham a oportunidade de pensar, verbalizar, refletir e organizar suas experiências de trabalho.

Com vistas à efetivação desse processo optamos por elaborar um modelo inicial de intervenção, o qual possa dar suporte e orientar as ações dos responsáveis.

1. O primeiro aspecto a ser definido é o modelo de encontro mais adequado para o desenvolvimento da proposta. Considerando a necessidade de um investimento de médio e longo prazo sugere-se a realização de reuniões sistemática com a presença de um grupo de coordenadores de núcleo, sob a mediação/ orientação de um tutor/ professor.

2. Outro aspecto relevante nesse tipo de trabalho é o papel assumido por coordenadores e tutor. Deve haver um esforço para construção de uma relação equilibrada, na qual o 
tutor procura dar voz aos coordenadores, conduzindo-os à reflexão de suas próprias práticas. Em momentos oportunos o tutor pode oferecer recursos e ferramentas que possam enriquecer a reflexão, mas o mesmo deve evitar assumir a postura de autoridade do conhecimento. Já os coordenadores devem ser conscientizados do seu protagonismo no trabalho, no sentido de que os rumos do trabalho dependem de seu comprometimento com a reflexão, evitando transferir para figura do tutor a responsabilidade do trabalho.
3. Para o desenvolvimento das reuniões sugerimos uma sequência progressiva de atividades, pautadas nos componentes / fases do processo reflexivo indicados por Gilbert e Trudel (2001). Nesse sentido, para cada um dos componentes serão encaminhadas algumas tarefas aos coordenadores, as quais, sob orientação do tutor, vão delineando o processo reflexivo. Para uma meIhor visualização desse processo apresentamos abaixo um quadro explicativo, contendo os componentes e suas respectivas tarefas.

\begin{tabular}{|c|c|c|c|}
\hline Fases & $\begin{array}{l}\text { Definição } \\
\text { das fases }\end{array}$ & Tarefas & Sugestões \\
\hline $1^{a}$ & $\begin{array}{l}\text { Dilemas da } \\
\text { aula }\end{array}$ & $\begin{array}{l}\text { - Nesse primeiro momento os coordena- } \\
\text { dores devem ser convidados a refletir } \\
\text { sobre os problemas e dilemas de seu } \\
\text { trabalho no núcleo do PST. } \\
\text { É possível encaminhar questões do tipo: } \\
\text { Pensando em sua realidade de trabalho } \\
\text { no PST elenque pelo menos dez situa- } \\
\text { ções que você considera problemáticas, } \\
\text { ou seja, situações que dificultam o de- } \\
\text { senvolvimento de seu trabalho. }\end{array}$ & $\begin{array}{l}\text { - Para facilitar as reflexões dos } \\
\text { coordenadores é possível } \\
\text { filmar um dia de trabalho } \\
\text { em um núcleo e nessa opor- } \\
\text { tunidade reproduzir aos co- } \\
\text { ordenadores. Obviamente, } \\
\text { tomando-se os devidos cuida- } \\
\text { dos éticos para evitar eventu- } \\
\text { ais constrangimentos. }\end{array}$ \\
\hline $2^{a}$ & $\begin{array}{l}\text { Papel } \\
\text { profissional }\end{array}$ & $\begin{array}{l}\text { - Nesse segundo momento os coordena- } \\
\text { dores devem refletir sobre o seu papel } \\
\text { profissional no PST. Para iniciar essa } \\
\text { reflexão, o tutor deve encaminhar al- } \\
\text { gumas leituras pertinentes à atuação do } \\
\text { coordenador no PST. } \\
\text { - Após a leitura é importante discutir as } \\
\text { principais ideias dos textos, em grupo. } \\
\text { Para finalizar o tutor deve solicitar aos } \\
\text { coordenadores que respondam a se- } \\
\text { guinte pergunta: Quais são os objeti- } \\
\text { vos de minha atuação no PST? E em } \\
\text { seguida troquem as respostas com os } \\
\text { colegas e avaliem em que medida as } \\
\text { mesmas são coerentes com os propósi- } \\
\text { tos do programa. }\end{array}$ & $\begin{array}{l}\text { - Leituras relevantes para esse } \\
\text { momento envolvem as di- } \\
\text { retrizes e objetivos do PST; } \\
\text { leitura de algum texto que } \\
\text { indique os objetivos dos } \\
\text { projetos sociais; leitura de } \\
\text { documentos que indiquem a } \\
\text { situação socioeconômica do } \\
\text { Brasil. O livro intitulado Ci- } \\
\text { dadão de Papel do jornalista } \\
\text { Gilberto Dimenstein pode ser } \\
\text { uma boa sugestão. }\end{array}$ \\
\hline
\end{tabular}




\begin{tabular}{|c|c|c|c|}
\hline Fases & $\begin{array}{l}\text { Definição } \\
\text { das fases }\end{array}$ & Tarefas & Sugestões \\
\hline $3^{a}$ & $\begin{array}{l}\text { Definição do } \\
\text { problema }\end{array}$ & 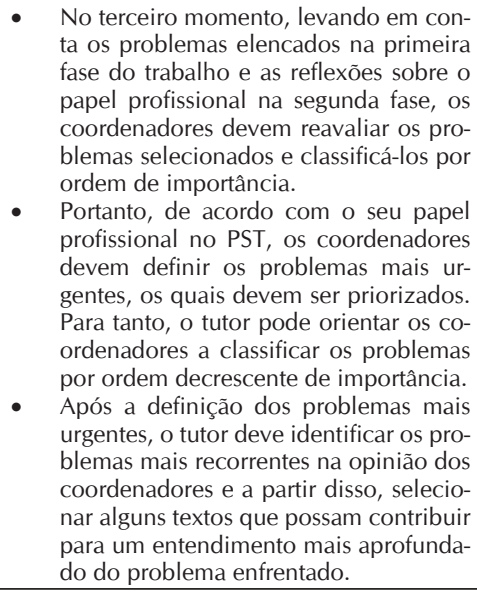 & $\begin{array}{l}\text { - O tutor deve empenhar-se na } \\
\text { pesquisa dos textos que pos- } \\
\text { sam de fato elucidar as situa- } \\
\text { ções problemáticas. } \\
\text { É possível convidar professo- } \\
\text { res experientes que já tenham } \\
\text { enfrentado algum problema } \\
\text { elencado, com o objetivo de } \\
\text { apresentar um relato de expe- } \\
\text { riência. }\end{array}$ \\
\hline $4^{a}$ & $\begin{array}{l}\text { Geração de } \\
\text { estratégias }\end{array}$ & $\begin{array}{l}\text { - No quarto momento o tutor deve orga- } \\
\text { nizar os coordenadores em duplas ou } \\
\text { trios, agrupando aqueles que identifica- } \\
\text { ram problemas comuns. } \\
\text { O trabalho dos coordenadores é refletir } \\
\text { e elaborar possíveis estratégias para so- } \\
\text { lução dos problemas. } \\
\text { Por fim, é importante formular uma } \\
\text { proposta de intervenção, por exemplo, } \\
\text { a elaboração de planos de aulas ou um } \\
\text { plano de intervenção. }\end{array}$ & $\begin{array}{l}\text { - O tutor pode ajudar os co- } \\
\text { ordenadores apresentando } \\
\text { experiências observadas em } \\
\text { outros convênios, pode indi- } \\
\text { car algum material didático e, } \\
\text { principalmente, apoiar os co- } \\
\text { ordenadores na formalização } \\
\text { da proposta. }\end{array}$ \\
\hline $5^{a}$ & & $\begin{array}{l}\text { - No quinto momento as estratégias de- } \\
\text { vem ser experimentadas em situações } \\
\text { reais de ensino, de preferência no coti- } \\
\text { diano de trabalho no núcleo. } \\
\text { Os resultados dessa experimentação } \\
\text { devem ser anotados em um diário de } \\
\text { aula pelos próprios coordenadores, ao } \\
\text { término das aulas. }\end{array}$ & $\begin{array}{l}\text { - O tutor pode oferecer um } \\
\text { exemplo de diário de aula e } \\
\text { que tipo de informações devem } \\
\text { ser anotada. O livro de Miguel } \\
\text { Zabalza (Diários de aula) pode } \\
\text { ser lido e discutido em algum } \\
\text { momento do processo para fo- } \\
\text { mentar estas ações. }\end{array}$ \\
\hline $6^{a}$ & Avaliação & 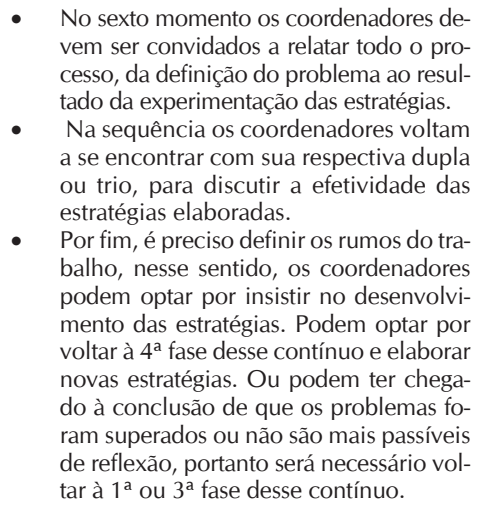 & $\begin{array}{l}\text { - O tutor pode ajudar os co- } \\
\text { ordenadores as registrar os } \\
\text { resultados encontrados. }\end{array}$ \\
\hline
\end{tabular}


4. Ao final do processo sugerimos ao tutor que encaminhe uma auto-avaliação do trabalho, na perspectiva dos coordenadores. Para tanto, os coordenadores devem ser estimulados a repensar sua atuação durante o trabalho de reflexão sobre suas práticas. Por fim, o tutor pode apresentar um relatório com suas impressões sobre o trabalho, os avanços e retrocessos, bem como os caminhos que devem ser percorridos para continuidade e consolidação das reuniões e do trabalho reflexivo.

\section{CONSIDERAÇÕES FINAIS}

O Programa Segundo Tempo obteve, nos últimos cinco anos, avanços significativos. A relevância do programa frente ao desafio de democratização do acesso ao esporte no Brasil pode ser observada na consolidação do mesmo como programa estratégico do Governo Federal e nas iniciativas de ampliação de seu oferecimento, como é o caso da parceria com o Ministério da Educação com vistas ao desenvolvimento do PST no contexto do Programa Mais Educação.

Outro aspecto que deve ser destacado é a consolidação dos pressupostos teórico-metodológicos que dão sustentação ao programa com a elaboração e publicação de dois livros, bem como a estruturação de um modelo de acompanhamento e avaliação dos convênios bastante efetivo.

Por outro lado, o grande desafio do Programa Segundo Tempo é proporcionar um salto de qualidade no desenvolvimento das práticas, no sentido de aproximar as aulas aos pressupostos idealizados pelo programa.
Reconhecemos que as dificuldades enfrentadas pelos coordenadores do PST na efetivação das propostas do programa perpassam uma série de condicionantes que envolvem o trabalho nos núcleos, dentre eles, optamos por refletir sobre as limitações impostas pelo atual modelo de capacitação.

Indicamos as limitações impostas por um modelo de capacitação pautado na racionalidade técnica, o descompasso entre o que se propõe nas capacitações e o que se observa no cotidiano das aulas e as dificuldades dos coordenadores em lidar com problemas complexos, instáveis e imprevisíveis da prática.

Nesse contexto, com o intuito de vislumbrar alternativas à realidade enfrentada pelos coordenadores de núcleo consideramos urgente a viabilização de propostas complementares de capacitação que atendam as demandas dos coordenadores de núcleo.

Para tanto, a partir dos pressupostos do professor reflexivo e considerando que os coordenadores de núcleo produzem saberes na reflexão de sua própria prática, apresentamos um modelo complementar de capacitação sustentado pela racionalidade prática.

Com isso, esperamos contribuir com a melhoria da prática pedagógica dos coordenadores de núcleo e consequentemente com a qualidade das aulas oferecidas às inúmeras crianças e adolescentes atendidas pelo PST.

Não se pode perder de vista que a efetividade do modelo que estamos propondo não pode ser simplesmente transposto, como uma receita a ser aplicada por cada equipe colaboradora em seus respectivos convênios, tendo em vista que esta simples transposição traria consigo o risco de 
incorporação das mesmas mazelas características do modelo da racionalidade técnica. É preciso assumir esta proposta como parâmetros gerais que orientem o trabalho das equipes colaboradoras em conjunto com seus respectivos convênios, deixando implícita uma margem de manobra para que esta ação consolide-se enquanto uma construção coletiva.

Por fim, cabe ressaltar ainda que nossa proposição não apresenta a pretensão de negar ou abandonar o projeto de capacitação em vigência. Mais do que uma mudança de conteúdo, propomos algumas alterações no que corresponde à forma. É evidente que, partindo do pressuposto de que o "novo paradigma" sustenta-se pelos dilemas oriundos da prática pedagógica, inevitavelmente haverá uma redefinição destes conteúdos a partir das demandas de cada contexto, mas não há como abandonar as diretrizes que orientam a política pública do programa, que se traduzem em temáticas tais como lazer, gênero e procedimentos metodológicos. Negar ou abandonar estas temáticas seria obrigar os diferentes atores do processo a "reinventarem a roda" incessantemente. Ao contrário, englobar as perspectivas das diretrizes do programa com a valorização das ações reflexivas oriundas da prática pode contribuir, sobremaneira, com o efetivo desenvolvimento do programa.

\section{REFERÊNCIAS}

BRACHT, V. Sociologia Crítica do Esporte: Uma Introdução. ljuí: Unijuí, 2011. 4 edição.

GILBERT, W. D; TRUDEL, P. Learning to coach through experience: reflection in model youth sport coaches. Journal of Teaching Physical Education, v.21, p.16-34, 2001.

HANSEN, F. R.; PERIM, G, L.; OLIVEIRA, A. A. B.. Apresentação. In: PERIM, G, L.; OlIVEIRA, A. A. B.. (Orgs.). Fundamentos Pedagógicos do Programa Segundo Tempo: da reflexão à prática. Maringá, Eduem, 2009.

MINISTÉRIO DO ESPORTE. Diretrizes do Programa Segundo Tempo 2011. Secretaria Nacional de Esporte Educacional. 2011. Disponível em: < http://portal.esporte.gov.br/ arquivos/snee/segundoTempo/ DiretrizesdoProgramaSegundoTempo. pdf > . Acesso em: 27 abr. 2012.

MINISTÉRIO DO ESPORTE. O Ministério. Ministério do Esporte. 2012. Disponível em: <http://www.esporte.gov.br/ institucional/ministerio.jsp $>$. Acesso em: 03 maio 2012.

NÓVOA, A. A formação de professores e a profissão docente. In: NÓVOA, A. Os professores e sua formação. $2^{a}$ ed. Lisboa: Dom Quixote, 1995.

PÉREZ GÓMEZ, A. I. O pensamento prático do professor - a formação do professor como profissional reflexivo. In: NÓVOA, A. Os professores e sua formação. $2^{\mathrm{a}}$ ed. Lisboa: Dom Quixote, 1995.

RANGEL BETTI, I. C; BETTI, M. Novas perspectivas na formação profissional em Educação Física. Motriz, v. 2, n.1, p. 10-15, 1996.

SCHON, D. A. Educando o profissional reflexivo: um novo design para o ensino e a aprendizagem. Porto Alegre: Artes Médicas Sul, 2000.

SOUSA, E. S. de; NORONHA, V.; RIBEIRO, C. A.; TEIXEIRA, D. M. D.; FERNANDES, D. M.; VENÂNCIO, M. A. D. Sistema 
de Monitoramento \& Avaliação dos Programas Esporte e Lazer da Cidade e Segundo Tempo do Ministério do Esporte. Belo Horizonte: O Lutador, 2010.

TUBINO, M. G. Estudos brasileiros sobre esporte: ênfase no esporte-educação. Maringá: Editora da UEM, 2010.
ZABALZA, M. A. Diários de aula: um instrumento de pesquisa e desenvolvimento profissional. Porto Alegre: Artmed, 2004.

SECOND TIME THE PROGRAM AND ITS TRAINING PROCESS: and analyzing the propositions

\section{ABSTRACT}

This study aimed to reflect about the training model of the "Programa Segundo Tempo", seeking to make proposals aimed to deepen the understanding about the regional training, including new looks for this process. For this, a discussion was held about the themes: the training process; the limits of the current training model; possible paths for the practice improvement. Finally, it was presented a proposal that would complement the current training model, based on assumptions of practical rationality, seeking for the improvement of training processes, valuing shares arising from the reflective practice so that real improvements can be made in the program's action.

Keywords: Social Project; Sport pedagogy; Professional training. 